\title{
Research Survey on Different MPP Tracking Optimization Algorithms for Solar Photovoltaic System (SPS)
}

\author{
${ }^{1}$ R. Mohan Kumar, ${ }^{2}$ Dr.C.Kathirvel \\ ${ }^{1}$ Assistant Professor, Department of EEE, Sri Ramakrishna Engineering College, Coimbatore, \\ Tamilnadu, India \\ ${ }^{2}$ Associate Professor, Department of EEE, Sri Ramakrishna Engineering College, Coimbatore, \\ Tamilnadu, India
}

\begin{abstract}
Due to increase in global warming, it is required to choose an alternative renewable energy source for the electricity generation. Among various renewable energy sources (RES), photo-voltaic energy is one of the most accessible source of energies. But the conversion rate of solar PV cell is about $25 \%$ to $40 \%$ of solar irradiation level. In Solar Photovoltaic (PV) system, to improve and maximize the operating efficiency level, Maximum Power Point Tracking (MPPT) techniques were required. Because of the change in the level of solar irradiance, and the nature of dynamic temperature, this MPP tracking will be highly important to make the solar PV system (SPS) to operate at higher efficiency level. This MPPT method is mainly categorized into three different types such as direct method, indirect method and intelligent method. This paper will gives and overview about various MPPT methods employed for solar PV system. Various controlling algorithms were discussed in this section for a better understanding.
\end{abstract}

Keywords: Maximum Power Point Tracking (MPPT), Photovoltaic (PV), Solar PV System (SPS)

\section{Introduction}

In the contemporary years, stand alone and hybrid solar PV system installation was increased among the individuals. Because of increase in demand of coal, petroleum, natural gas, oils and energy demand, an alternative source of energy is required. Also, the environment factors are to be considered in order to reduce the pollution. To overcome these problems, non-conventional or renewable source of energies like solar energy, wind energy, biomass, hydro, etc are comes into picture. Among various energy sources, solar PV system plays significant role in the electric energy generation. The main advantages of the solar PV system are no carbon emission, abundant in nature, less maintenance, environment friendly and no need of fuel. Due to these advantages, this solar PV system is more widely deployed as distributed generation system.

Even though there are many advantages, the implementation of SPS is a great challenge due to its installation cost. Further the SPS does not give a constant output to the load because of partial shading conditions, irradiation level of solar and environmental temperature. Also, the conversion efficiency rate is less. In order to overcome the above problems, it is mandatory to design and develop a MPPT algorithm which could be used for extorting highest power from the panels of PV. The important aim of this paper is to bring a new optimization algorithm which will extract utmost power generation from solar PV system during various environmental situations.

\section{Solar Cell Characteristics}

The solar cell converts the light energy into electric energy directly. Solar cells are basically made from semiconductor materials. Photovoltaic (PV) cells are generally made of silicon material which is mainly designed to absorb photons from sun light and convert them into electric energy. The main important electrical attributes of PV cell or module are explained with the assistance of the accompanying parameters.

First, current due to the intensity of solar irradiation and second is the voltage which is mostly independent of intensity of light. These two parameters will tell us about the conversion rate or effectiveness of a solar PV cell. Sort-circuit current of PV cell during maximum irradiance level is represented as $I_{\mathrm{sc}}$. It is the maximum current delivered by the PV cell without creating any damage to the solar cell during short-circuit condition. It is the ratio between maximum short circuit current to the surface area exposed to the light intensity. $\mathrm{V}_{\mathrm{oc}}$ is called as open-circuit voltage of photovoltaic cell without connecting any load. The $\mathrm{V}_{\mathrm{oc}}$ value of single solar cell is ranging from $0.5 \mathrm{~V}$ to $0.6 \mathrm{~V}$. The relationship between the open-circuit voltage and the short-circuit current is explained in graph. 


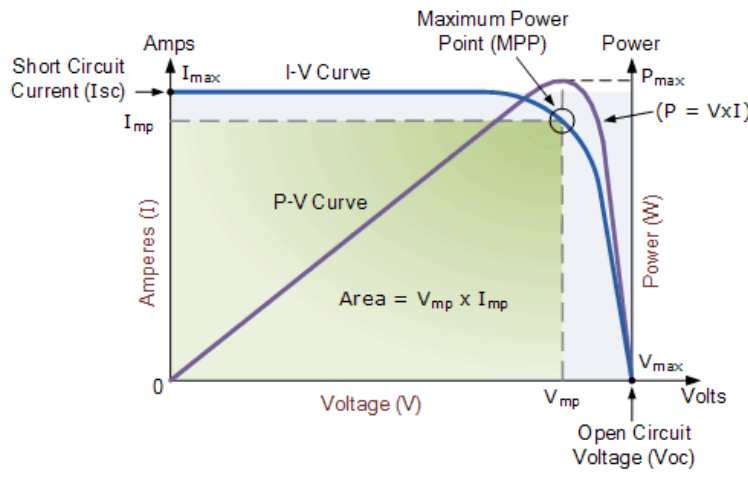

Figure 1. Characteristics of Photo Voltaic Cell

\subsection{Maximum Power Point Tracking}

There was very low conversion rate in the PV arrays. To build the productivity rate of PV board, the Maximum Power Point Tracking (MPPT) control method was needed. This is an automatic technique of control method that will automatically adjust the interfacing power system and achieve highest power production through the solar PV system during various conditions of sunlight. By utilizing the MPPT algorithm, the solar PV operating voltage will adjust very near to the MPP due to the change in environmental conditions. Because of this reason, the MPPT controller becomes the heart of solar PV conversion system. This paper will provide an idea about the different techniques, methodologies and implementations of MPPT controller for the grid-tie and independent PV system. The intelligent methods are used to improve the efficacy rate of the solar power conversion in addition to reduce oscillations at MPP under steady state condition. Moreover, by using the intelligent techniques, the tracking of MPP is very fast when compared with the conventional methods. Different types of MPPT algorithms have its own advantages and disadvantages, which could be seen one by one in this paper.

\subsection{Types of MPPT Algorithm}

The MPPT techniques are more important in Solar PV system for extracting the high power during its operation. The different kinds of MPPT techniques were listed here for better understanding.

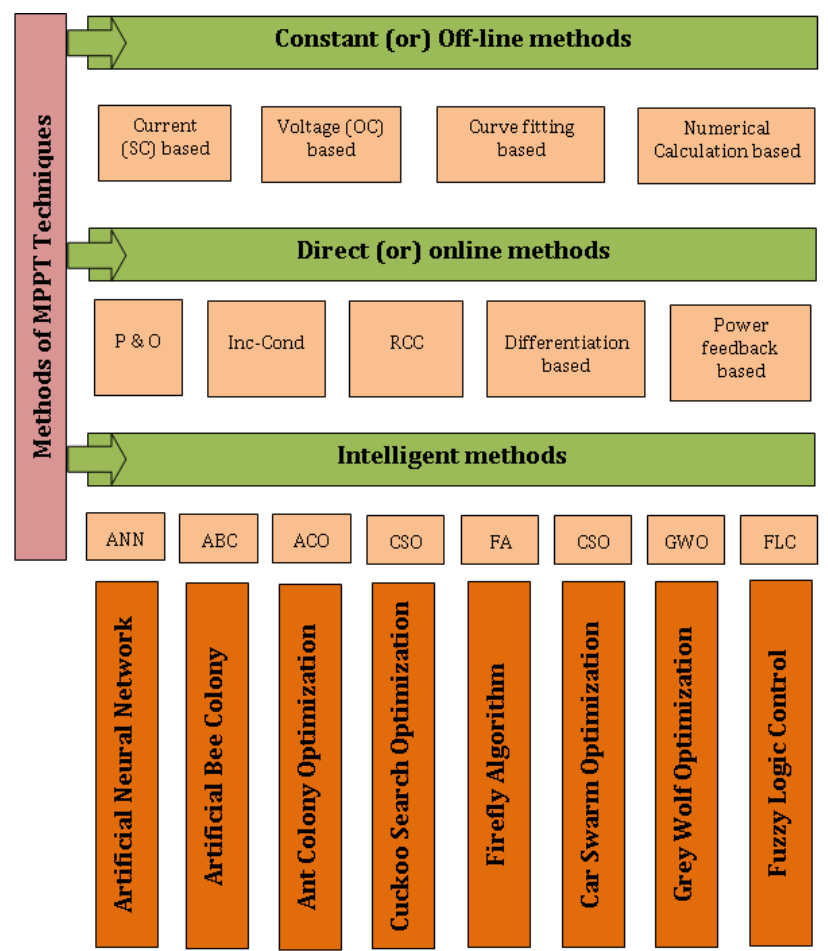

Figure 2. Classification of Optimization Algorithms 


\section{Various Types of Optimization Algorithm}

\subsection{Constant or Offline Methods}

There are many offline methods of MPP tracking algorithms were developed namely constant (open-circuit) voltage, curve-fitting method, numerical methods, short-circuit current method and look-up table methods. These offline methods are more effective and efficient for lower rating PV systems. Also, it has less cost effective and easy implementation due its simplest structure. These methods give the measurements in a very precise manner which is the main advantage of these techniques. Fast tracking speed and steady state operations during the change in irradiance level and temperature level are also the advantages. But these techniques are not viable and not suitable for higher rating PV systems. To overcome these disadvantages, direct or online methods will be developed which ensures the optimal efficiency.

\subsection{Direct or Online Method}

The Direct or Online methods are notable as Model Free technique. In these methods, the instantaneous attributes of solar PV system voltages and currents are measured which could be used for the generation of control signals. Many online methods are encountered like P\&O (Perturbation \& Observation) Method, IncCond (Incremental Conductance) Method, Differentiation based method and Power Feedback methods. More number of researches were done in this context and develop a real-time controllers due its accuracy. Out of these, P\&O method could be implemented with reference voltage magnitude and current magnitude from the solar PV panel. It is the most widely used approach among the other methods. PWM technique is used in this method for the generation of control signals. But in IncCond method, the incline of solar PV attributes were used in generating the control signals. During MPP, the incline of PV characteristics are equal to zero. For smaller data of power output, the slope is positive and for the greater data of power output, the slope is negative.

Even though there are many advantages in these online methods, there are some disadvantages. In P\&O method, the tracking is somewhat slower during smaller perturb steps and there is an oscillation but faster tracking during higher perturb steps. When compared with the traditional methods of MPPT, these methods are more complex for the implementation. In $\mathrm{P} \& \mathrm{O}$ method, there are some oscillations under steady-state condition which occurs during the peak point power tracking. This is due to the continuous perturbation changes in the direction to maintain the MPP during the partial shading condition also under dynamic irradiance level. This lessens the proficiency of the system and also increases the power loss. While in IncCond method, by choosing bigger step size which reduces the time of tracking but the oscillations will remains there.

Also in other side, smaller step size enhance its efficiency level by reducing the fluctuations under changing irradiance level. But, there is a reduction in the tracking speed of solar PV system. The Ripple Correlation Controller Method result in more complexity of implementation due to its derivative components. To overcome all these disadvantages, intelligent control methods are used and furthermore the system dynamic performance increases periodically.

\subsection{Intelligent Control Methods}

In order to have a very high working outcome of solar photovoltaic system, the MPPT methods were applied to the control over the exhibition of the PV framework under consistent state and dynamic conditions. So many intelligent control methods were developed and implemented, such as Artificial Neural Network, Cuckoo Search Optimization, Firefly Algorithm, Artificial Bee Colony, Car Swarm Optimization, Fuzzy Logic Control, Ant colony Optimization, Grey Wolf Optimization and goes on.

Also many hybrid techniques were evolved by combining the above methods which eliminates the disadvantages in each method. This soft computing techniques were used in the MPP tracking due to its fast response of tracking, and also reduces the fluctuations during dynamic conditions. ANN is one of the Machine learning techniques which resembles the human biological nerve system. In ANN, the convergence rate is fast, and it has the ability to handle the non-linearity conditions. But the system implementation requires high cost when compare with other systems.

Fuzzy Logic control method replicates the expert knowledge of human to make the control signal decisions. The unknown system is treated to model the non-precise data with experience knowledge and rule based. The time-consumption is more in this method and also it is very complex to implement.

Among many intelligent control methods, the recently developed Grew Wolf Optimization technique is more effective and efficient in tracking. Constraints such as lesser tracking efficacy, oscillations under steady-state condition and transients during operations are eliminated by implementing this GWO method. During partial shading conditions, this GWO gives a very good working efficiency of photovoltaic system. 


\subsection{Grew Wolf Optimization Technique}

The new method of optimization technique is introduced based on the nature inspired meta-heuristic algorithm called Grey Wolf Optimization (GWO) technique. The natural hunting mechanisms and leadership behavior of grey wolves are described to develop the mathematical model of GWO algorithm. By considering the grey wolves, the hunting mechanisms are approached as mathematical models with the pinnacle of food chain. There were four different varieties of wolves like Alpha wolf $(\alpha)$, Beta $(\beta)$ wolf, Delta $(\delta)$ wolf and Omega $(\omega)$ wolf. When compared these wolves with the mathematical model of MPPT algorithm, the first fittest solution the alpha and beta is the second fittest solution and then the third is the delta. The last one omega are the candidate solutions, and which can be entitled to use for next iterations.

In GWO, there are three important steps to be incorporate as per the hunting mechanism. First hunting, chasing of prey, and monitoring of prey, secondly encircle the prey and the last attacking prey. The above said is implemented for the GWO optimization to track the MPP. Mainly the alpha wolf is guide the rest of the wolves and act as a leader. While beta wolves and delta wolves will follow the instructions from the alpha. Omega wolves are continuously participate in the hunting mechanism by fix the boundary area of the prey. In case, the alpha wolves are not available due ageing, beta wolves will act in the position of alpha wolf. That is the first fittest solution is not available due to any error or unavoidable condition, in such case, the second fittest solution (beta) will be considered as the fittest solution.

This emerging optimization technique will results in quick convergences. The meta-heuristic optimization algorithms are growing more among the researchers due the following advantages: (i) simple to execute with its basic concepts, (ii) easy convergence with large amount of data, (iii) does not require gradient information and (iv) solution accuracy is high with less controlling parameters. Lower tracking efficiency, oscillations during steady-state condition and transients during operation are the major issues faced during MPPT of solar PV system (SPS) by using other optimization techniques. This GWO technique will definitely overcome the above issues and explore the best solution for the complicated MPPT problems in solar photovoltaic system. This GWO mathematical approach will enhance researchers to apply it for different optimization problems.

\section{Conclusion}

The important privilage of utilizing the solar energy is to provide the solution for the environmental impacts, and also for the demand of electrical energy. Due to the recent development of various MPPT algorithms, there is an improvement in efficacy of the photovoltaic system. In this paper, different MPPT optimization methods for the SPS are talked about and a broad overview was given. The present MPPT methods were utilized to enhance the effectiveness of PV system by including different types of control strategies, circuit elements, and end user applications. This paper gives an idea for the possible ways and means for selecting a particular MPPT technique for a specific process both in grid-tie mode and in independent mode of working.

It is noted that the IncCond and P\&O methods are easy to implement under lower rating of solar PV system. But they have less tracking efficiency. In order to eliminate the above disadvantage, fuzzy logic control, neural network, ant colony optimization and other intelligent control methods were introduced and implemented. Even though they are much better than $\mathrm{P} \& \mathrm{O}$ and IncCond methods, they have fluctuations during operation which is one of the main drawbacks in these systems. By using the GWO technique, it had the option to follow the peak power point during partial shading situations, dynamic temperatures and also during dust conditions. This heuristic development of GWO MPPT algorithm kindle an interest in researchers to develop a new hybrid optimization technique for the improvisation of SPS efficiency.

\section{References}

1. Mazen Abdel-Salam, \&Mohammed Lasheen.(2018). Maximum Power Point Tracking using Hill Climbing and ANFIS Techniques for PV Applications: a Review and a Novel Hybrid Approach.Energy Conversion and Management, 171:1002-1019.

2. Altin, N. (2018). The Type-2 Fuzzy Logic Controller-Based Maximum Power Point Tracking Algorithm and the Quadratic Boost Converter for PV System.Journal of Electronic Materials, vol. 47, 4475-4485.

3. Krishna Kumar Paliwal, Vishal Dabra, Pradeep Sharma \&Narender Kumar. (2017). Optimization of Photovoltaic Power System: A comparative study.Protection and Control of Modern Power Systems.

4. Robandi, I.,\& Darmansyah. (2017). Photovoltaic Parameter Estimation using Grey Wolf Optimization, $3^{\text {rd }}$ International Conference on Control, Automation and Robotics, 593-597. 
5. Ahmed Faheem Zobaa, Ramdan, B. A., Koad \& Adel El-Shahat. (2017). A Novel MPPT Algorithm based on Particle Swarm Optimization for Photovoltaic Systems.IEEE Transactions on Sustainable Energy, vol. 8, no. 2, 468-476.

6. Jordehi, A., Rezaee. (2016). Maximum Power Point Tracking in Photovoltaic (PV) Systems: a Review of Different Approaches.Renewable and Sustainable Energy Reviews, Elsevier, 1127-1138.

7. Vidhya, K., Viswambaran, Erping Zhou, \& Arfan Ghani. (2016). Modelling and Simulation of Maximum Power Point Tracking Algorithms and Review of MPPT Techniques for PV Applications. $5^{\text {th }}$ International Conference on Electronic Devices, Systems and Applications, 1-4.

8. Bidyadhar Subudhi, Satyajit Mohanty, \& Pravat Kumar Ray. (2016). A Grey Wolf Optimization Based MPPT for PV System under Changing Insolation Level.IEEE Transactions on Sustainable Energy, 175179.

9. Wazedur Rahman,Md., Chaitanya Bathina, Karthikeyan, V.,\& Prasanth, R. (2016). Comparative Analysis of Developed Incremental Conductance (IC) and Perturb \& Observe (P\&O) MPPT Algorithm for Photovoltaic Application.10 International Conference on Intelligent Systems and Control, 1-6.

10. Pallavi, T., Sawant, Lbhattar, P. C.,\& Bhattar, C. (2016). Enhancement of PV System Based on Artificial Bee Colony Algorithm under Dynamic Conditions.IEEE International Conference on Recent Trends in Electronics, Information \& Communication Technology, 1251-1255.

11. Ankit Gupta, Yogesh, K., Chauhan \& Rupendra Kumar Pachauri. (2016). A Comparative Investigation of Maximum Power Point Tracking Methods for Solar PV System.Journal of Solar Energy, Elsevier Science, 136, 236-253.

12. Huynh,D. C., Matthew Dunnigan, W. (2015). Maximum Power Point Tracking using an Adaptive Perturbation and Observation Algorithm for a Grid-Connected Solar Photovoltaic System. International Journal of Grid and Distributed Computing 8(3):97-110.

13. Mohanty, S.,Subudhi, B., \& Ray, P. K. (2015). A New MPPT Design using Grey Wolf Optimization Technique for Photovoltaic System under Partial Shading Conditions. IEEE Transactions on Sustainable Energy7 181-188.

14. Rahul Tapre, G.,\& Prof. Deshbhratar, R. G. (2015). Comparative Study and Simulation of Different Maximum Power Point Tracking (MPPT) Techniques in a Solar Power Generation.International Journal on Recent and Innovation Trends in Computing and Communication, vol. 3, 143-148.

15. Lina Elobaid, M., Ahmed Abdelsalam, K., \& Ezeldin Zakzouk, E. (2015). Artificial Neural NetworkBased Photovoltaic Maximum Power Point Tracking Techniques: a Survey.IET Renewable Power Generation, vol. 9, no. 8, 1043-1063.

16. Yi-Hua Liu, Jing-Hsiao Chen, \&Jia-Wei Huang. (2015). A review of Maximum Power Point Tracking Techniques for use in Partially Shaded Conditions.Renewable and Sustainable Energy Reviews.

17. Hadi Malek,\& YangQuan Chen. (2014). BICO MPPT: a Faster Maximum Power Point Tracker and its Application for Photovoltaic Panels. International Journal of Photoenergy, 41:436-453.

18. Kante Visweswara. (2014). An Investigation of Incremental Conductance based Maximum Power Point Tracking for Photovoltaic System.Energy Procedia, vol. 54, 11-20.

19. Ahmed Jubaer,\& Salam Zainal. (2014). A Maximum Power Point Tracking (MPPT) for PV System using Cuckoo Search with Partial Shading Capability.Journal of Applied Energy, Elsevier, 119, 118130.

20. Yue, M.,\& Wang, X. (2014). A Revised Incremental Conductance MPPT Algorithm for Solar PV Generation Systems.http://arxiv.org/abs/1405.4890.

21. Mohamed Eltawil, A.,\& Zhengming Zhao. (2013). MPPT Techniques for Photovoltaic Applications.Elsevier Renewable and Sustainable Energy Reviews, vol. 25, 793-813.

22. William Christopher, I.,\& Ramesh, R. (2013). Comparative Study of P\&O and InC MPPT Algorithms.American Journal of Engineering Research, 2 402-408.

23. Altin, N. (2013). Interval Type-2 Fuzzy Logic Controller Based Maximum Power Point Tracking in Photovoltaic Systems.Advances in Electrical and Computer Engineering, vol. 13, 65-70, 2013.

24. Kashif Ishaque,\& Zanial Salam. (2013). A review of Maximum Power Point Tracking Techniques of PV System for Uniform Insolation and Partial Shading Condition.Renewable and Sustainable Energy Reviews, vol. 19, pp. 475-488.

25. Ali Reza Reisi, Mohammed Hassan Moradi, \& Shahriar Jamasb. (2013). Classification and Comparison of Maximum Power Point Tracking Techniques for Photovoltaic System: a Review. Renewable and Sustainable Energy Reviews, vol. 19, 433-443.

26. Pallavee Bhatnagar, \&Nema, R.K. (2013). Maximum Power Point Tracking Control Techniques: Stateof-the-art in Photovoltaic Applications.Elsevier Renewable and Sustainable Energy Reviews, vol. 23, 224-241. 
27. Mohammed Elgendy, A., Bashar Zahawi, \& David Atkinson, J. (2012). Assessment of Perturb and Observe MPPT Algorithm Implementation Techniques for PV Pumping Applications. IEEE Transactions on Sustainable Energy, vol. 3, no. 1, 21-33.

28. Kashif Ishaque, Zainal Salam, Muhammad Amjad \& Saad Mekhilef. (2012). An Improved Particle Swarm Optimization (PSO) - Based MPPT for PV with Reduced Steady-State Oscillation. IEEE Transactions on Power Electronics, vol. 27, no. 8, 3627-3638.

29. Alberto Dolara, Faranda, R.,\& Leva, S. (2009). Energy Comparison of Seven MPPT Techniques for PV Systems.Journal of Electromagnetic Analysis and Applications, vol. 1, no. 3, 152-162.

30. Dezso Sera, Remus Teodorescu, Jochen Hantschel \& Michael Knoll. (2008). Optimized Maximum Power Point Tracker for Fast Changing Environmental Conditions.IEEE Transactions on Industrial Electronics, 2401-2407.

31. Hiren Patel \& Vivek Agarwal. (2008). Maximum Power Point Tracking Scheme for PV Systems Operating under Partially Shaded Conditions.IEEE Transaction Industrial Electronics, 55(4), 16891698.

32. Adel Mellit \& Soteris Kalogirou, A. (2008). Artificial Intelligence Techniques for Photovoltaic Applications: a Review.Progress in Energy and Combustion Science, vol. 34, no. 5, 574-632.

33. Trishan Esram \& Chapman, P. L. (2007). Comparison of Photovoltaic Array Maximum Power Point Tracking Techniques.IEEE Transactions on Energy Conversion, vol. 22, no. 2, 439-449.

34. Koizumi, H.,\& Kurokawa, K. (2006). A Novel Maximum Power Point Tracking Method for PV Module Integrated Converter.In Proceedings of the IEEE $36^{\text {th }}$ Power Electronics Specialists Conference, IEEE, 2081-2086. 